Fanum

Sociológico
Forum Sociológico

Série II

26 | 2015

Número 26

\title{
Modelos Sociais Europeus - Crescimento, emprego e igualdade
}

\section{Eduardo Viegas Ferreira}

\section{(2) OpenEdition \\ 12 Journals}

\section{Edição electrónica}

URL: https://journals.openedition.org/sociologico/1184

DOI: 10.4000/sociologico.1184

ISSN: 2182-7427

\section{Editora}

CICS.NOVA - Centro Interdisciplinar de Ciências Sociais da Universidade Nova de Lisboa

\section{Edição impressa}

Data de publição: 12 dezembro 2015

Paginação: 17-29

ISSN: 0872-8380

\section{Refêrencia eletrónica}

Eduardo Viegas Ferreira, «Modelos Sociais Europeus - Crescimento, emprego e igualdade», Forum Sociológico [Online], 26 | 2015, posto online no dia 04 abril 2016, consultado o 29 março 2022. URL: http://journals.openedition.org/sociologico/1184 ; DOl: https://doi.org/10.4000/sociologico.1184 


\title{
MODELOS SOCIAIS EUROPEUS - CRESCIMENTO, EMPREGO E IGUALDADE
}

\author{
Eduardo Viegas Ferreira \\ Universidade Lusíada de Lisboa
}

\begin{abstract}
Resumo
As recentes crises financeiras e económicas relançaram a discussão acerca dos efeitos dos modelos sociais europeus sobre o crescimento económico e a criação de emprego. Recorrendo à tipologia seminal de Esping-Andersen (1990) e aos dados estatísticos oficiais atualmente disponíveis, este artigo compara alguns desempenhos económicos e sociais, antes e depois da crise global de 2008, de estados-membros da União Europeia. Os resultados obtidos sugerem que, após 2008, ocorreu uma aproximação entre os principais modelos sociais ideal-típicos europeus, traduzida num mais generalizado trade off entre menor crescimento e mais desemprego e menor desigualdade económica e menor risco de pobreza. Os resultados obtidos também sugerem que competitividade, crescimento económico e emprego foram compatíveis com baixos níveis de desigualdade na distribuição do rendimento entre capital, trabalho e inatividade.
\end{abstract}

Palavras-chave: modelos sociais europeus; risco de pobreza; desigualdade; crescimento económico

\begin{abstract}
The discussion on the effects of the European social models on economic growth and employment regained importance following the recent financial and economic crisis. Following the tradition of Esping-Andersen (1990), the aim of this article is to apply a "typologies of social models" perspective to identify selected economic and social performances before and after the 2008 crisis. Results obtained from available official data suggest that differences diminished after 2008 due to a more generalised trade off between lower economic growth and higher unemployment, and lower inequality and risk of poverty. Results also suggest that economic competitiveness and growth were compatible with lower levels of unequal income distribution among capital, labour and inactivity.
\end{abstract}

Keywords: european social models; risk of poverty; inequality; economic growth

\section{Os modelos sociais europeus}

A visão, nascida no pós-Segunda Guerra Mundial, de uma União Europeia baseada na igualdade, na não-discriminação, numa justa distribuição do rendimento e na solidariedade, foi-se consolidando ao longo da segunda metade do século XX. No entanto, a implementação de um modelo social, comum à União e capaz de concretizar esta visão, foi e continua longe de ser uma realidade.

Como mostrou Esping-Andersen (1990; 1996; 2000), na última década do século XX ainda coexistiam na União diferentes visões de sociedade e diferentes variações do que se poderia designar como um modelo social europeu. Similitudes e diferenças nos graus de comodificação do trabaIho, na forma como governos, mercados e famílias interagiam e se responsabilizavam pela proteção face a riscos sociais, nos níveis de estratificação e de solidariedade e na distribuição de recursos pelos diferentes grupos sociais, configuravam pelo menos três modelos sociais ideal-típicos: o liberal, o corporativista/estatista e o social-democrata. Um quarto tipo, o mediterrânico, viria a ser proposto por Ferrera (1996) e Bonoli (1997).

Pesquisas posteriores, como as realizadas por Sapir (2006) e Hermann e Hofbauer (2007), mostraram a persistência destas variações. Apesar de apresentar algumas caraterísticas que o distinguiam de modelos existentes noutras regiões do mundo, o 
modelo social europeu (Leibfried, 2000) continuava a caraterizar-se por uma diversidade resultante de diferentes combinações entre regimes de proteção social, sistemas fiscais e contributivos e sistemas de relações laborais (Hyman, 2005).

Os estados-membros da União Europeia têm sido invariavelmente agrupados no modelo liberal (Irlanda e Reino Unido); no modelo social-democrata (Dinamarca, Finlândia e Suécia); no modelo corporativista (Alemanha, Austria, Bélgica, França e Holanda); e no modelo mediterrânico (Espanha, Grécia, Itália e Portugal). ${ }^{1}$

O modelo liberal tem-se distinguido pela visão de uma sociedade em que indivíduos, famílias e empresas devem poder escolher, com a menor intervenção possível do governo, as opções que mais benefícios lhes assegurem, a si e à sociedade. Indivíduos, famílias e empresas devem também responsabilizar-se por acautelar a sua própria proteção face a riscos futuros. Uma das consequências desta visão tem residido numa constante tentativa para manter, em níveis mínimos, a intervenção do governo na proteção social, nomeadamente por via de restrições, quer no acesso a prestações sociais, condicionando-o a prova de absoluta necessidade e incapacidade, quer na duração das mesmas. Outra consequência tem residido numa reduzida intervenção governamental nas relações produtivas e laborais. A legislação laboral tende a ser flexível em termos de contratualizações, bem como em relação à sua cessação, e associações patronais e sindicais têm uma intervenção reduzida no estabelecimento, por exemplo, de acordos coletivos de trabalho. Devido à importância dada ao trabalho como instrumento de obtenção de rendimento e de inclusão social, a proteção assegurada no desemprego tende a ser reduzida e condicionada (Huber e Stephens, 2005; Sapir, 2006; Aiginger e Leoni, 2009).

O modelo social-democrata tem-se distinguido pela visão de uma sociedade em que governo e o maior número possível de organizações e associações sociais cooperam para assegurar a maior igualdade possível de oportunidades no acesso ao bem-estar e às condições que a tornam possível. A visão social-democrata tem subjacente que, se necessário, o governo deve intervir na eliminação das discriminações existentes e na redução das desigualdades, forçando uma redistribuição do rendimento, quer através de um sistema fiscal fortemente progressivo, quer através de contribuições sociais obrigatórias que assegurem uma proteção social tendencialmente universal e suficiente. A possibilidade de a maioria da população em idade ativa poder aceder ao trabalho e ao rendimento oriundo deste, sem discriminações nem desigualdades de idade ou género, entre outras, tem sido um valor estruturante da visão social-democrata, concretizado num permanente diálogo e numa estreita cooperação entre governo e parceiros sociais, numa elevada participação sindical e num elevado envolvimento dos sindicatos na negociação e contratualização laboral. Elevadas taxas de sindicalização e de abrangência de acordos coletivos de trabalho limitam, por norma, desequilíbrios excessivos entre capital e trabalho. Uma eficaz proteção social no desemprego começou a ser complementada, ainda no século passado, por incentivos à procura ativa de emprego (Huber e Stephens, 2005; Sapir, 2006; Aiginger e Leoni, 2009).

O modelo corporativista tem-se distinguido pela visão de uma sociedade muito semelhante à social-democrata. A principal diferença tem residido no pressuposto de que o governo deve intervir menos na criação das condições que garantem igualdade, não-discriminação, mais equitativa distribuição do rendimento e maior solidariedade. No entanto, ao contrário do modelo liberal, não existe uma forte condicionalidade no acesso a prestações ou subsídios sociais. Apesar de as taxas de sindicalização serem, por norma, mais baixas do que no modelo social-democrata, associações sindicais e patronais assumem um papel determinante na negociação de acordos coletivos de trabalho, nacionais, setoriais ou empresariais, bem como na manutenção de um equilíbrio entre proteção do emprego e no desemprego. Os sistemas fiscais e contributivos são menos progressivos do que no modelo social-democrata e a despesa pública com proteção social, quer em situações de doença, incapacidade, desemprego ou risco de pobreza e exclusão social, quer com incentivos à reintegração no mercado de trabalho, também é, por norma, menor e menos universal (Huber e Stephens, 2005; Sapir, 2006; Aiginger e Leoni, 2009).

O modelo mediterrânico tem-se distinguido pela visão de uma sociedade que incorpora valores do modelo corporativista e do modelo liberal. Neste último caso, a visão é menos individualista, na medida em que a proteção social é entendida como devendo ser mais partilhada por redes, mais ou menos alargadas, de suporte familiar. As visões contraditórias que têm marcado este modelo derivam, em parte, do facto de terem persistido, até aos anos $70 / 80$ do século $X X$, regimes políticos totalitários em Espanha, Portugal e Grécia, com regimes públicos de proteção social muito rudimentares e que privilegiavam os grupos mais leais aos regimes nomeadamente as forças armadas e de segurança e o funcionalismo público. Esta não-universalidade da proteção social foi, até aos anos 50/60 do século $X X$, uma característica distintiva de alguns estados corporativistas (Esping-Andersen, 1990). A persistência de uma desconfiança na capacidade, ou na vontade, do governo para assegurar uma proteção social universal tem estado associada a uma também persistente resistência à transferência de recursos, quer por via de impostos, quer por via 
de contribuições sociais, para o domínio público. As consequências têm sido uma menor abrangência da proteção social garantida pelo governo, uma maior condicionalidade no acesso a prestações e subsídios. Apesar das reduzidas taxas de sindicalização, associações sindicais e patronais têm um peso importante, quer na adoção de legislação laboral protetora do emprego e penalizadora do despedimento, quer na negociação e contratação coletiva. Dois dos efeitos desta tendência, para a proteção do emprego, têm sido uma reduzida e muito condicionada proteção social no desemprego e uma frequente opção por políticas de reforma antecipada que permitam assegurar uma maior empregabilidade da população ativa mais jovem. A tradição clientelar e particularista, ou casuísta, dos regimes de proteção social tem-se traduzido numa persistente concentração dos (mais reduzidos) recursos alocados a proteção social em apenas alguns grupos sociais (Ferrera, 1996; Huber e Stephens, 2006; Sapir, 2006; Aiginger e Leoni, 2009).

Estas distinções, bem como a integração dos estados-membros da União num destes quatro modelos, ainda hoje são discutidas quanto à sua pertinência teórica e empírica (Hemerijck, 2013). No entanto, este agrupamento ideal-típico continua a constituir um instrumento importante de análise, na medida em que, através da redução, sempre relativa e discutível, é certo, de inúmeras especificidades nacionais, permite comparar conjuntos de estados quanto aos seus desempenhos quer em termos de crescimento económico e de criação de emprego, quer de redução de desigualdades económicas e de situações de risco de pobreza, tal como foi objetivo deste estudo.

\section{Reconfigurações e desempenhos económicos e sociais nos quatro modelos no início do século XXI}

As três últimas décadas do século $X X$ foram marcadas por sucessivas crises e períodos de recessão económica. O ritmo médio de crescimento económico abrandou após a primeira crise petrolífera, nos anos 70 , e este abrandamento acentuou-se durante e após as crises registadas no Reino Unido (anos 80) e na Suécia, Finlândia e Alemanha recentemente reunificada (anos 90). Em meados da década de 90, o número de desempregados, no conjunto na União Europeia, atingiu um valor recorde (Dølvik e Martin, 2014; Wood et al., 2014) e a discussão sobre que modelo social era mais eficiente para voltar a relançar o crescimento e o emprego acentuou-se.

A crise que afetou o Reino Unido lançou as primeiras dúvidas sobre os efeitos de leis protetoras do emprego e de associações sindicais com um forte poder negocial, de uma elevada despesa pública e elevados impostos e contribuições e de uma elevada inflação. Estes fatores foram associados à decadência económica do Reino Unido e ao desemprego que atingia, no final da década de 70, um milhão e meio de trabalhadores. Liberalização das leis e relações laborais, redução do peso dos sindicatos nas negociações e contratualizações e redução do peso da despesa (e receita) pública aproximaram gradualmente o Reino Unido do modelo liberal. Os resultados foram inicialmente contraditórios. A inflação foi controlada, a economia voltou a crescer mas o desemprego duplicou e, no final da década de oitenta, apenas tinha regredido para o valor que se registava uma década antes. Por outro lado, no final da década de 80 o Reino Unido tinha perdido grande parte da sua capacidade produtiva de bens manufaturados e estava a tornar-se uma economia dominada pelo setor terciário (Stronach,1990).

A crise que afetou, no início dos anos 90, a Suécia e a Finlândia reforçou as dúvidas sobre os efeitos de despesas e receitas públicas demasiado elevadas. Recessão económica e elevados níveis de desemprego foram apontados como sendo o resultado, entre outros fatores, de sistemas fiscais e contributivos e de regimes de proteção social demasiado generosos, bem como de sistemas de relações laborais desequilibradas em favor do trabalho. Na realidade, parte da crise na Suécia teve origem nos setores imobiliário e financeiro, ou seja, nos mesmos setores que viriam a estar na origem da crise global de 2008. Confrontada com o custo público da intervenção necessária para resgatar o sistema financeiro, bem como com o avolumar do peso da despesa pública e com um Produto Interno Bruto e uma receita pública em queda acentuada, a Suécia optou por reestruturar o regime de proteção social, tornando-o mais condicional, menos universal e mais direcionado para a procura ativa de emprego, bem como o seu sistema fiscal e contributivo e a sua legislação e relações laborais. No entanto, acabaria por manter razoavelmente intactas as principais caraterísticas do modelo social-democrata - universalidade, não-discriminação e prestações sociais adequadas e suficientes a uma mais rápida reintegração na vida ativa (Ryner, 1999). No caso da Finlândia, a crise também teve origem no setor financeiro e na extensiva desregulamentação do mesmo que teve lugar no início dos anos 80. À semelhança do que ocorreu na Suécia, o esforço financeiro exigido, entre 1991 e 1993, para resgatar os bancos levou este país a optar por uma reestruturação do seu regime de proteção social e do seu sistema fiscal e contributivo (Honkapohja e Koskela, 1999).

A crise que afetou, nos primeiros anos da década de 90, a Alemanha recém-reunificada também contribuiu para reforçar as dúvidas sobre os efeitos de uma elevada despesa pública, em particular com proteção social. Neste caso, os custos da recuperação 
da ex-Alemanha de Leste e o consequente aumento do défice das contas públicas foram, em conjunto com uma crescente inflação, fatores apontados para a depressão económica e para o aumento do desemprego. Embora a intervenção do Banco Central Alemão, aumentando as taxas de juro com receio de uma inflação incontrolada e dos efeitos dos défices públicos muito elevados, tenha tido um papel importante nesta crise (Ghaussy e Schäfer, 2002), o resultado foi a opção por uma reestruturação do regime de proteção social e dos sistemas fiscal e contributivo e, em menor, extensão, do próprio sistema de relações laborais.

$\mathrm{Na}$ última década do século $\mathrm{XX}$ cresceu a convicção de que os regimes de proteção social, os sistemas fiscais e contributivos e os sistemas de relações laborais caraterísticos do modelo social-democrata e do modelo corporativista constituíam um entrave ao crescimento económico e à criação de emprego, em particular num mundo crescentemente caraterizado pelo livre-comércio e livre-circulação de capitais, pessoas e bens (Blyth, 2002; Pierson, 1994). O trade off, no sentido originalmente atribuído à expressão por Okun (1975), conseguido pelo modelo liberal, mais crescimento e mais emprego em troca de maior desigualdade económica e maior risco de pobreza, era então evidente, mas, apesar de algumas incertezas quanto aos desempenhos, a médio e longo prazo, em termos de crescimento económico e criação de emprego (Emmenegger, 2011), reduções da despesa com proteção social e com outras funções sociais passaram a ser abertamente sugeridas como necessárias para reduzir os custos sociais imputados ao capital e ao trabalho no, genérico, modelo social europeu.

Os efeitos da redução da despesa com proteção social, em sociedades caraterizadas por agregados familiares cada vez menos numerosos e por um peso crescente de uma terceira idade inativa e muito dependente de regimes públicos de proteção social, foram claramente subestimados. Deixar às forças dos mercados o equilíbrio entre os interesses divergentes do trabalho e do capital, responsabilizar famílias e indivíduos pela prevenção e pela sua própria proteção face a riscos sociais e relançar o gosto e a motivação pelo trabalho eram imperativos para que as economias europeias voltassem a ser globalmente competitivas (Kwon et al., 2009).

A visão de que famílias e indivíduos só tinham a ganhar uma redução dos custos com uma proteção social, então considerada como demasiado generosa e pouco meritocrática e, não raras vezes, folcloricamente como promotora da preguiça, da aversão ao risco e do parasitismo, também ignorou evidências que mostravam que os mercados, quando deixados a funcionar de acordo com as suas leis, mantêm, quando não acentuam, elevadas e persistentes desigualdades económicas, bem como sociais e políticas (Kangas e Palme, 2009; Esping-Andersen, 2005).

A possibilidade de famílias e indivíduos, que, à partida, não tinham recursos suficientes para competir nos mercados em igualdade de circunstâncias, poderem ser excluídos do bem-estar assegurado pelo crescimento económico, devido à ausência de mecanismos sociais de reequilíbrio e redistribuição de recursos (Kangas e Palme, 2009; Krugman, 2008; Barr, 2001), foi, no entanto, encarada como um custo inevitável face à premência de promover crescimento económico e emprego.

Os estados mais afetados pelas crises, ocorridas nas últimas décadas do século $X X$, introduziram reformas, de amplitude variada consoante os equilíbrios políticos e sociais nacionais, nos sistemas de relações laborais, nos sistemas fiscais e contributivos e nos regimes de proteção social. No entanto, no início do século XXI a convergência para um único modelo social estava longe de se ter concretizado. Apesar das reformas efetuadas, os estados-membros da União ainda apresentavam, em 2001, vincadas diferenças, nomeadamente ao nível do peso, nos respetivos Produtos Internos Brutos, quer na despesa com proteção social e na receita com impostos e contribuições sociais, quer nas taxas de sindicalização (Quadro 1).

Os estados social-democratas destacavam-se pelo mais elevado peso médio, no Produto Interno Bruto, da receita com impostos e contribuições sociais, bem como por possuírem as mais elevadas taxas de sindicalização. Destacavam-se, ainda, em conjunto com os estados corporativistas, por alocarem uma maior percentagem média do seu Produto Interno Bruto a proteção social, isto é, a prestações, subsídios e apoios, em dinheiro e em espécie, destinados a compensar situações de inatividade ou de rendimento insuficiente.

Os restantes estados apresentavam, em média, quer uma menor despesa com proteção social e uma menor receita fiscal e contributiva, quer taxas de sindicalização mais baixas. A homogeneidade interna de cada modelo-tipo apenas era colocada em causa, no modelo social-democrata, pela Finlândia, no modelo corporativista pela Holanda e, no modelo liberal, pelo Reino Unido, que, em 2001, parecia estar mais próximo do modelo social-democrata, em termos de despesa com proteção social, do que do modelo liberal.

Apesar destas diferenças, nenhum dos quatro modelos se destacava, quando globalmente considerado, quanto aos seus desempenhos sociais, antes de contabilizadas transferências sociais, em dinheiro ou em espécie, no rendimento disponível. Isto é, quanto à sua capacidade de redução da desigualdade económica e do risco de pobreza. Diferenças acentuadas só se verificavam após a contabilização de tais transferências (Quadro 2). 
Quadro $1 \triangleright$ Despesa com proteção social, receita pública com impostos e contribuições sociais e taxa de sindicalização (2001)

\begin{tabular}{|c|c|c|c|}
\hline & $\begin{array}{l}\text { Despesa com proteção } \\
\text { social (em \% do PIB) }\end{array}$ & $\begin{array}{l}\text { Receita com impostos } \\
\text { e contribuições sociais } \\
\text { (em \% do PIB) }\end{array}$ & $\begin{array}{c}\text { Taxa de sindicalização } \\
(\text { em \%) }\end{array}$ \\
\hline Modelo social-democrata & 28,2 & 45,9 & 75,3 \\
\hline Dinamarca & 29,2 & 47,4 & 73,3 \\
\hline Finlândia & 25,0 & 43,0 & 74,5 \\
\hline Suécia & 30,4 & 47,4 & 78,0 \\
\hline Modelo corporativista & 28,2 & 41,9 & 29,0 \\
\hline França & 29,6 & 44,1 & 7,9 \\
\hline Áustria & 28,6 & 45,0 & 35,9 \\
\hline Alemanha & 29,7 & 39,3 & 23,7 \\
\hline Bélgica & 26,4 & 45,0 & 56,3 \\
\hline Holanda & 26,5 & 36,3 & 21,2 \\
\hline Modelo mediterrânico & 22,7 & 35,6 & 24,7 \\
\hline Itália & 24,8 & 40,0 & 34,2 \\
\hline Grécia & 24,3 & n.d. & 25,8 \\
\hline Portugal & 21,9 & 33,2 & 22,4 \\
\hline Espanha & 19,7 & 33,6 & 16,4 \\
\hline Modelo liberal & 20,4 & 33,0 & 33,7 \\
\hline Reino Unido & 26,6 & 36,2 & 29,5 \\
\hline Irlanda & 14,1 & 29,8 & 37,8 \\
\hline
\end{tabular}

Fontes: EUROSTAT e OCDE Data Bases. ${ }^{2}$

Quadro $2 \triangleright$ Desempenho social em 2001

\begin{tabular}{|c|c|c|c|c|}
\hline \multirow[b]{3}{*}{ Modelo social-democrata } & \multicolumn{2}{|c|}{$\begin{array}{l}\text { Desigualdade económica } \\
\text { (índice de Gini) }^{3}\end{array}$} & \multicolumn{2}{|c|}{$\begin{array}{c}\text { Risco de pobreza (em \% da população } \\
\text { residente) }\end{array}$} \\
\hline & $\begin{array}{c}\text { (antes } \\
\text { de transferências } \\
\text { sociais) }\end{array}$ & $\begin{array}{l}\text { (depois } \\
\text { de transferências } \\
\text { sociais) }\end{array}$ & $\begin{array}{c}\text { (antes } \\
\text { de transferências } \\
\text { sociais) }\end{array}$ & $\begin{array}{c}\text { (depois } \\
\text { de transferências } \\
\text { sociais) }\end{array}$ \\
\hline & 46 & 24 & 36,7 & 10,0 \\
\hline Dinamarca & 46 & 22 & 36,0 & 10 \\
\hline Finlândia & n.d. & 27 & 40,0 & 11 \\
\hline Suécia & n.d. & 24 & 34,0 & 9 \\
\hline Modelo corporativista & 49 & 26 & 38,8 & 12,0 \\
\hline França & n.d. & 27 & 44,0 & 13 \\
\hline Áustria & 46 & 24 & 38,0 & 12 \\
\hline Alemanha & n.d. & 25 & 39,0 & 11 \\
\hline Bélgica & 51 & 28 & 38,0 & 13 \\
\hline Holanda & n.d. & 27 & 35,0 & 11 \\
\hline Modelo mediterrânico & 49 & 33 & 38,8 & 19,5 \\
\hline Itália & n.d. & 29 & 42,0 & 19 \\
\hline Grécia & 49 & 33 & 39,0 & 20 \\
\hline Portugal & n.d. & 37 & 37,0 & 20 \\
\hline Espanha & n.d. & 33 & 37,0 & 19 \\
\hline Modelo liberal & 44 & 32 & 39,0 & 19,5 \\
\hline Reino Unido & n.d. & 35 & 42,0 & 18 \\
\hline Irlanda & 44 & 29 & 36,0 & 21 \\
\hline
\end{tabular}

Fonte: EUROSTAT Data Base.

Os desempenhos sociais médios em cada modelo-tipo apenas eram diferentes, em 2001, após a intervenção dos regimes de proteção social. Depois de contabilizadas transferências sociais, os estados corporativistas e social-democratas apresen- tavam, em média, índices de desigualdade e riscos de pobreza muito inferiores. Estas diferenças não estavam associadas apenas ao peso mais elevado da despesa com proteção social. Elas estavam também associadas a uma distribuição, mais universalista 
nos estados social-democratas e corporativistas, das transferências sociais efetuadas para grupos com uma potencial maior vulnerabilidade socioeconómica (Quadro 3).

Embora o peso da despesa com pensões de reforma e de sobrevivência e com apoios vários à terceira idade fosse acentuado em praticamente todos os estados, os social-democratas e os corporativistas destacavam-se pelas transferências para portadores de deficiência ou doença, famílias e crianças e desempregados - pese embora o facto de, neste último caso, tal estar em parte associado às mais elevadas taxas de desemprego, então existentes, em alguns estados social-democratas e corporativistas.

Os piores desempenhos sociais dos estados liberais e mediterrânicos foram compensados por melhores desempenhos económicos. No período compreendido entre 1995 e 2001, a evolução do Produto Interno Bruto, a preços constantes, foi, em média, maior em todos os estados liberais e mediterrânicos. Nos primeiros, o ritmo médio de redução da taxa de desemprego foi também assinalável e, em 2001, possuíam as mais baixas taxas de desemprego. Os estados mediterrânicos, pelo contrário, possuíam as mais elevadas taxas de desemprego (Quadro 4).

Os desempenhos económicos dos estados social-democratas (Suécia e Finlândia) e corporativistas (Alemanha) que maiores reformas tinham efetuado na última década do século XX eram, no entanto, inferiores, quer aos dos estados liberais, quer aos da maioria dos restantes estados-membros. Apesar dos resultados, algo contraditórios, das reformas efetuadas, as acentuadas diferenças médias, existentes em 2001, em termos de crescimento económico e de geração de emprego reforçaram a convicção que uma maior competitividade e um maior crescimento só seriam conseguidos através da redução de impostos e contribuições sociais, da despesa pública, em particular com proteção social, e de uma maior flexibilização, ou liberalização, das relações laborais.

\section{Reconfigurações e desempenhos}

económicos e sociais entre o início do século e a crise de 2008

A introdução da moeda única europeia, uma relativa expansão económica, a continuação de reformas em alguns estados-membros e a adesão, entre 2004 e 2007, de novos estados marcaram a União nos primeiros sete anos do século XXI. No entanto, as principais caraterísticas dos modelos-tipo não se alteraram de forma acentuada. O movimento liberalizador, iniciado no final do século XX, teve efeitos na Suécia, Alemanha, Áustria e Reino Unido ao nível da redução do peso médio da despesa com proteção social, mas nos restantes estados este manteve-se ou aumentou. O peso médio da receita com impostos e contribuições sociais manteve-se ou diminuiu na maioria dos estados social-democratas e corporativistas mas

Quadro $3 \triangleright$ Despesa com proteção social em 2001 (em percentagem do PIB), por principais destinatários das transferências efetuadas

\begin{tabular}{lcccc} 
& $\begin{array}{c}\text { Terceira idade } \\
\text { e sobreviventes }\end{array}$ & $\begin{array}{c}\text { Portadores } \\
\text { de doença } \\
\text { prolongada } \\
\text { ou deficiência }\end{array}$ & $\begin{array}{c}\text { Famílias } \\
\text { e crianças }\end{array}$ & Desempregados \\
Modelo social-democrata & $\mathbf{1 0 , 4}$ & $\mathbf{1 0 , 3}$ & $\mathbf{3 , 2}$ & $\mathbf{2 , 3}$ \\
\hline Dinamarca & 10,8 & 9,3 & 3,8 & 2,8 \\
Finlândia & 8,9 & 9,3 & 2,9 & 2,4 \\
Suécia & 11,6 & 12,2 & 2,8 & 1,8 \\
Modelo corporativista & $\mathbf{1 1 , 7}$ & $\mathbf{9 , 8}$ & $\mathbf{2 , 4}$ & $\mathbf{1 , 9}$ \\
\hline França & 12,3 & 9,7 & 2,5 & 2,0 \\
Áustria & 13,3 & 9,7 & 2,9 & 2,4 \\
Alemanha & 12,1 & 10,9 & 3,2 & 2,9 \\
Bélgica & 10,6 & 8,5 & 2,1 & 1,2 \\
Holanda & 10,4 & 10,4 & 1,1 & $\mathbf{1}, \mathbf{2}$ \\
Modelo mediterrânico & $\mathbf{1 1 , 1}$ & $\mathbf{7 , 6}$ & $\mathbf{1 , 2}$ & 0,4 \\
\hline Itália & 14,9 & 7,4 & 1,1 & 1,4 \\
Grécia & 12,1 & 7,3 & 1,6 & 0,7 \\
Portugal & 8,8 & 8,4 & 1,1 & 2,1 \\
Espanha & 8,6 & 7,3 & 0,9 & $\mathbf{1 , 1}$ \\
Modelo liberal & $\mathbf{7 , 7}$ & $\mathbf{7 , 9}$ & $\mathbf{1 , 9}$ & 0,9 \\
\hline Reino Unido & 11,9 & 9,5 & 1,7 & 1,2
\end{tabular}

Fonte: EUROSTAT Data Base. 
Quadro $4 \backslash$ Desempenho económico no início do século XXI

\begin{tabular}{lccc} 
Modelo social-democrata & $\begin{array}{c}\text { Evolução do PIB } \\
\text { entre } \mathbf{1 9 9 5} \mathbf{2 0 0 1} \\
(\mathbf{2 0 0 0 = 1 0 0 )}\end{array}$ & $\begin{array}{c}\text { Evolução da taxa } \\
\text { de desemprego } \\
\text { entre } \mathbf{1 9 9 5} \text { e 2001 }\end{array}$ & $\begin{array}{c}\text { Taxa de desemprego } \\
\text { em 2001 }\end{array}$ \\
\hline Dinamarca & $\mathbf{+ 8 , 3}$ & $\mathbf{- 3 , 8}$ & $\mathbf{6 , 5}$ \\
Finlândia & $+10,2$ & $-2,2$ & 4,5 \\
Suécia & $+7,3$ & $-6,3$ & 9,1 \\
Modelo corporativista & $+7,5$ & $-3,0$ & 5,8 \\
\hline França & $\mathbf{+ 3 , 7}$ & $-\mathbf{2 , 3}$ & $\mathbf{5 , 8}$ \\
Áustria & $+6,5$ & $-2,4$ & 7,8 \\
Alemanha & $-0,3$ & $-0,2$ & 3,6 \\
Bélgica & $-2,2$ & $-0,4$ & 7,8 \\
Holanda & $+2,9$ & $-3,1$ & 6,6 \\
Modelo mediterrânico & $+11,6$ & $-5,2$ & 3,1 \\
\hline Itália & $\mathbf{2 0 , 2}$ & $-\mathbf{3 , 9}$ & $\mathbf{8 , 9}$ \\
Grécia & $+23,5$ & $-2,2$ & 9,0 \\
Portugal & $+24,7$ & $-0,4$ & 10,7 \\
Espanha & $+16,8$ & $-2,8$ & 5,1 \\
Modelo liberal & $+15,6$ & $-10,1$ & 10,6 \\
\hline Reino Unido & $\mathbf{2 9 , 5}$ & $-\mathbf{6 , 0}$ & $\mathbf{4 , 5}$ \\
Irlanda & $+33,2$ & $-3,5$ & 5,0
\end{tabular}

Fonte: EUROSTAT Data Base.

aumentou na maioria dos estados mediterrânicos e na Irlanda. A diminuição das taxas de sindicalização constituiu a única tendência comum à maioria dos estados, tendo sido particularmente acentuada nos estados social-democratas (Quadro 5).

Antes da crise de 2008, mantinham-se as principais diferenças entre os modelos-tipo, apenas se tendo acentuado algumas das divergências que já se manifestavam em 2001 e tendo emergido novas divergências e convergências. Na Finlândia e Holanda, por exemplo, ocorreu uma convergência para o modelo corporativista. No Reino Unido continuou a registar-se uma aproximação ao modelo liberal, enquanto na Irlanda ocorreu uma divergência

Quadro 5 \ Evolução, entre 2001 e 2007, da despesa com proteção social, da receita pública com impostos e contribuições sociais e da taxa de sindicalização

\begin{tabular}{lccc} 
Modelo social-democrata & $\begin{array}{c}\text { Despesa } \\
\text { com proteção social } \\
\text { (em \% do PIB) }\end{array}$ & $\begin{array}{c}\text { Receita } \\
\text { com impostos } \\
\text { (emtribuições sociais }\end{array}$ & $\begin{array}{c}\text { Taxa do PIB) } \\
\text { de sindicalização } \\
\text { (em \%) }\end{array}$ \\
\hline Dinamarca & $\mathbf{0 , 2}$ & $\mathbf{- 1 , 2}$ & $\mathbf{- 5 , 5}$ \\
Finlândia & 1,5 & 0,0 & $-5,4$ \\
Suécia & 0,4 & $-1,7$ & $-4,0$ \\
Modelo corporativista & $-1,2$ & $-1,8$ & $-7,2$ \\
\hline França & $\mathbf{0 , 2}$ & $\mathbf{- 1 , 2}$ & $\mathbf{- 2 , 7}$ \\
Áustria & 1,3 & $-0,1$ & $-0,4$ \\
Alemanha & $-0,7$ & $-3,7$ & $-6,0$ \\
Bélgica & $-2,0$ & $-0,8$ & $-3,8$ \\
Holanda & 0,5 & $-1,2$ & $-1,6$ \\
Modelo mediterrânico & 1,8 & $-0,1$ & $-1,9$ \\
\hline Itália & $\mathbf{1 , 4}$ & $\mathbf{1 , 0}$ & $\mathbf{- 1 , 1}$ \\
Grécia & 1,8 & 1,5 & $-0,7$ \\
Portugal & 0,5 & $n . d$. & $-1,3$ \\
Espanha & 2,0 & 1,7 & $-1,6$ \\
Modelo liberal & 1,1 & 3,2 & $-0,7$ \\
\hline Reino Unido & $\mathbf{1 , 0}$ & $\mathbf{0 , 8}$ & $-\mathbf{4 , 0}$ \\
Irlanda & $-1,9$ & $-0,4$ & $-1,6$ \\
\hline
\end{tabular}

Fonte: EUROSTAT e OCDE Data Bases. 
deste, registando-se um aumento do peso da despesa com proteção social, bem como dos impostos e contribuições sociais.

Em 2007, os estados social-democratas continuavam a apresentar, em média, a mais elevada despesa com proteção social e a mais elevada receita fiscal e contributiva, bem como a mais elevada taxa de sindicalização e a mais elevada taxa de abrangência de contratos de trabalho por acordos coletivos. Apresentavam ainda o segundo mais elevado índice de flexibilidade laboral. Os estados liberais continuavam a apresentar a mais baixa despesa com proteção social e a mais baixa receita fiscal e contributiva, bem como a mais baixa taxa de abrangência de contratos de trabalho por acordos coletivos e o mais elevado índice de flexibilidade laboral. Continuavam a apresentar, no entanto, a segunda mais elevada taxa de sindicalização (Quadro 6). ${ }^{5}$

As semelhanças, em termos de desempenhos económicos, eram assinaláveis, tal como o foi a emergência dos estados mediterrânicos como aqueles com um melhor desempenho em termos de evolução do Produto Interno Bruto (Quadro 7). Por outro lado, os desempenhos económicos dos estados que mais reformas efetuaram (Suécia, Alemanha e Reino Unido) continuaram a ser inferiores ao expetável, sobretudo quando comparados com os desempenhos dos que menos reduziram os ritmos de crescimento da despesa com proteção social (como a Dinamarca, França, Holanda, Itália, Portugal, Espanha, Irlanda).
Em 2007, a piores desempenhos económicos, nos estados que haviam apostado numa gradual liberalização, juntavam-se piores desempenhos sociais, em particular após contabilizadas as transferências sociais. O risco de pobreza havia aumentado na Suécia, Alemanha e Reino Unido e o índice de desigualdade também havia aumentado na Alemanha.

\section{Desempenhos económicos e sociais após 2008}

Os estados-membros responderam de forma diferenciada à crise de 2008. Diferentes compromissos e equilíbrios institucionais e políticos internos deram origem a diferentes reformas e, em geral, verificou-se uma maior discursividade de apoio ao relançamento económico e ao emprego na Europa através de reduções da despesa e da receita pública e de uma maior flexibilização das leis laborais (Hermann, 2014a). Esta discursividade foi evidente nas principais instituições europeias, que não cessaram de pressionar os estados para que adotassem e implementassem medidas para a estabilização das finanças públicas e privadas e para a promoção do crescimento económico (Hermann, 2014b).

Readaptar os regimes de proteção social a uma lógica de investimento social, isto é, levá-los a implementar reduções graduais mas sustentadas das transferências sociais passivas e incondicionais e a aumentar as que incentivassem a empregabilidade, tornou-se outra crescente sugestão discursiva (Van

Quadro $6 \triangleright$ Despesa com proteção social, receita pública com impostos e contribuições sociais, taxa de sindicalização, abrangência de acordos coletivos de trabalho e índice de flexibilidade laboral (2007)

\begin{tabular}{|c|c|c|c|c|c|}
\hline & $\begin{array}{c}\text { Despesa } \\
\text { com proteção social } \\
\text { (em \% do PIB) }\end{array}$ & $\begin{array}{c}\text { Receita } \\
\text { com impostos } \\
\text { e contribuições } \\
\text { sociais } \\
\text { (em \% do PIB) }\end{array}$ & $\begin{array}{c}\text { Taxa } \\
\text { de sindicalização } \\
(\mathrm{em} \%)\end{array}$ & $\begin{array}{c}\text { Abrangência } \\
\text { dos acordos } \\
\text { coletivos } \\
\text { de trabalho }(\mathrm{em} \%)\end{array}$ & $\begin{array}{c}\text { Índice } \\
\text { de flexibilidade } \\
\text { laboral }\end{array}$ \\
\hline Modelo social-democrata & 28,4 & 44,8 & 69,7 & 97,0 & 71,7 \\
\hline Dinamarca & 30,7 & 47,4 & 67,9 & 96,0 & 99,9 \\
\hline Finlândia & 25,4 & 41,3 & 70,5 & 98,0 & 49,9 \\
\hline Suécia & 29,2 & 45,6 & 70,8 & n.d & 65,2 \\
\hline Modelo corporativista & 28,3 & 40,8 & 26,3 & 84,3 & 61,2 \\
\hline França & 30,9 & 44,0 & 7,5 & 98,0 & 54,3 \\
\hline Áustria & 27,9 & 41,3 & 29,9 & 95,0 & 73,6 \\
\hline Alemanha & 27,7 & 38,5 & 19,9 & 48,0 & 48,7 \\
\hline Bélgica & 26,9 & 43,8 & 54,7 & 96,0 & 68,0 \\
\hline Holanda & 28,3 & 36,2 & 19,3 & n.d & 61,5 \\
\hline Modelo mediterrânico & 24,0 & 36,6 & 23,6 & 65,3 & 55,2 \\
\hline Itália & 26,6 & 41,5 & 33,5 & 96,0 & 74,5 \\
\hline Grécia & 24,8 & 33,3 & 24,5 & n.d & 56,1 \\
\hline Portugal & 23,9 & 34,9 & 20,8 & 30,0 & 41,2 \\
\hline Espanha & 20,8 & 36,8 & 15,7 & 70,0 & 48,8 \\
\hline Modelo liberal & 21,4 & 33,8 & 29,7 & 35,0 & 78,6 \\
\hline Reino Unido & 24,7 & 35,8 & 27,9 & 35,0 & 79,0 \\
\hline Irlanda & 18,0 & 31,8 & 31,5 & n.d & 78,2 \\
\hline
\end{tabular}

Fonte: EUROSTAT, OCDE, ILO (Internacional Labor Organization) e Heritage Foundation Data Bases. ${ }^{6}$ 
Quadro $7 \not$ Desempenho económico e social em 2007

\begin{tabular}{|c|c|c|c|c|c|c|}
\hline \multirow[b]{3}{*}{ Modelo social-democrata } & \multicolumn{2}{|c|}{ Evolução entre 2001 e 2007} & \multicolumn{2}{|c|}{ Índice de desigualdade } & \multicolumn{2}{|c|}{ Risco de pobreza } \\
\hline & PIB & $\begin{array}{c}\text { Taxa } \\
\text { de desemprego }\end{array}$ & $\begin{array}{c}\text { Antes } \\
\text { de transferências }\end{array}$ & $\begin{array}{c}\text { Depois } \\
\text { de transferências }\end{array}$ & $\begin{array}{c}\text { Antes } \\
\text { de transferências }\end{array}$ & $\begin{array}{c}\text { Depois } \\
\text { de transferências }\end{array}$ \\
\hline & 9,8 & $-0,9$ & 45,3 & 24,9 & 39,7 & 11,7 \\
\hline Dinamarca & 14,7 & $-0,7$ & 45,2 & 25,2 & 36,6 & 11,7 \\
\hline Finlândia & 5,6 & $-2,2$ & 46,4 & 26,2 & 41,1 & 13,0 \\
\hline Suécia & 9,0 & 0,3 & 44,3 & 23,4 & 41,5 & 10,5 \\
\hline Modelo corporativista & 11,8 & 0,8 & 48,5 & 27,4 & 41,9 & 13,1 \\
\hline França & 13,5 & 0,2 & 49,9 & 26,6 & 45,8 & 13,1 \\
\hline Áustria & 10,6 & 1,3 & 46,3 & 26,2 & 43,4 & 12,0 \\
\hline Alemanha & 6,4 & 0,7 & 54,4 & 30,4 & 43,2 & 15,2 \\
\hline Bélgica & 14,2 & 0,9 & 46,7 & 26,3 & 41,5 & 15,2 \\
\hline Holanda & 14,1 & 1,1 & 45,4 & 27,6 & 35,4 & 10,2 \\
\hline Modelo mediterrânico & 20,7 & $-0,9$ & 48,4 & 33,8 & 41,0 & 19,5 \\
\hline Itália & 16,0 & $-2,9$ & 47,8 & 32,2 & 43,4 & 19,8 \\
\hline Grécia & 19,6 & $-2,3$ & 49,4 & 34,3 & 41,9 & 20,3 \\
\hline Portugal & 19,3 & 4,1 & 51,0 & 36,8 & 40,0 & 18,1 \\
\hline Espanha & 28,0 & $-2,4$ & 45,4 & 31,9 & 38,6 & 19,7 \\
\hline Modelo liberal & 13,1 & 0,6 & 49,3 & 32,0 & 40,9 & 17,9 \\
\hline Reino Unido & 4,5 & 0,3 & 50,4 & 32,6 & 41,7 & 18,6 \\
\hline Irlanda & 21,7 & 0,8 & 48,2 & 31,3 & 40,1 & 17,2 \\
\hline
\end{tabular}

Fonte: EUROSTAT Data Base.

Kersbergen e Hemerijck, 2012). Adotar regimes contributivos duais, públicos e privados, ou simplesmente reduzir os descontos obrigatórios para os regimes públicos, mesmo correndo o risco de, a médio e longo prazo, tal resultar em rendimentos de pensões pouco acima dos limiares de pobreza, foi uma terceira crescente sugestão discursiva (Bridgen e Meyer, 2014).

A não-transferência destas discursividades para a realidade foi, no entanto, uma quase constante até 2012, último ano para o qual estão disponíveis dados oficiais validados. Nenhum estado, incluindo os que tiveram de ser financeiramente resgatados, reduziu de forma acentuada o peso, no Produto Interno Bruto, da despesa com proteção social. Por outro lado, poucos (apenas Suécia, Espanha, Reino Unido e Irlanda) reduziram o peso da receita com impostos e contribuições.

Em traços gerais, a convergência entre discursividades de apoio ao modelo liberal e realidade quantificável apenas se manifestou, nos estados social-democratas e no Reino Unido, na redução das taxas de abrangência de acordos coletivos de trabalho e, na Áustria, Bélgica, Espanha e Irlanda, no aumento do índice de flexibilidade laboral (Quadro 8).

A despesa com proteção social concentrou-se, no entanto, ainda mais em prestações destinadas à terceira idade e à sobrevivência, em parte à custa, como ocorreu na Suécia, Grécia e Portugal, das prestações destinadas a apoiar situações de deficiência ou doença e famílias e crianças (Quadro 9). O aumento, particularmente acentuado, nos estados liberais e em alguns estados mediterrânicos, do peso das prestações sociais destinadas a desempregados refletiu, por sua vez, uma reorientação necessária face a um aumento das taxas de desemprego.

A crise financeira de 2008 refletiu-se quase de imediato nos estados liberais e na Suécia. Nos restantes, os efeitos, em termos de redução dos ritmos de crescimento económico e de aumento do desemprego, só se fizeram sentir em 2009. Uma consequente crise, a das designadas dívidas soberanas, ocorreu em 2012 e afetou a generalidade dos estados europeus e, em particular, Grécia, Portugal, Espanha e Irlanda. Neste contexto, financeira e economicamente muito adverso, os estados social-democratas tiveram, pelo menos até 2013, o melhor desempenho médio em termos de evolução do Produto Interno Bruto e o segundo melhor desempenho médio em termos de contenção do desemprego. Os estados corporativistas revelaram, por sua vez, o melhor desempenho em termos de contenção do desemprego, mas em larga medida apenas devido à Alemanha e à Áustria (Quadro 10).

A Suécia, o estado social-democrata que mais conteve e reajustou a despesa com proteção social e que mais reduziu o peso de impostos e contribuições, mas também o que revelou um movimento mais acentuado no sentido de uma maior proteção do emprego, teve os melhores desempenhos económicos. No entanto, os estados onde parece ter ocorrido uma menor liberalização, como a Dinamarca, Finlândia, Áustria e Bélgica, também revelaram um razoável desempenho, quer em termos de evolução do Produto Interno Bruto, quer de relativa contenção do aumento do desemprego. 
Quadro $8 \triangleright$ Despesa com proteção social, receita com impostos e contribuições sociais, taxa de sindicalização, abrangência de acordos coletivos de trabalho e índice de flexibilidade laboral (evolução em relação a 2007 e últimos valores disponíveis)

\begin{tabular}{|c|c|c|c|c|c|c|c|c|c|c|}
\hline \multirow[b]{3}{*}{ Modelo social-democrata } & \multicolumn{2}{|c|}{$\begin{array}{l}\text { Despesa } \\
\text { com proteção social } \\
\text { (em \% do PIB })\end{array}$} & \multicolumn{2}{|c|}{$\begin{array}{c}\text { Receita } \\
\text { com impostos } \\
\text { e contribuiçōes } \\
\text { sociais } \\
\text { (em \% do PIB) }\end{array}$} & \multicolumn{2}{|c|}{$\begin{array}{c}\text { Taxa } \\
\text { de sindicalização } \\
(\mathrm{em} \%)\end{array}$} & \multicolumn{2}{|c|}{$\begin{array}{l}\text { Taxa } \\
\text { de abrangência } \\
\text { de acordos } \\
\text { coletivos } \\
\text { de trabalho } \\
(\mathrm{em} \%)\end{array}$} & \multicolumn{2}{|c|}{$\begin{array}{c}\text { Índice } \\
\text { de flexibilidade } \\
\text { laboral }\end{array}$} \\
\hline & Var & 2012 & Var & 2014 & Var & 2014 & Var & 2014 & Var & 2014 \\
\hline & 3,7 & 32,1 & 1,8 & 46,6 & $-1,7$ & 68,0 & $-10,7$ & 86,3 & $-8,1$ & 63,5 \\
\hline Dinamarca & 3,9 & 34,6 & 4,0 & 51,4 & $-0,9$ & 67,0 & $-16,0$ & 80,0 & $-8,7$ & 91,2 \\
\hline Finlândia & 5,8 & 31,2 & 2,7 & 44,0 & $-1,5$ & 69,0 & $-7,0$ & 91,0 & $-3,4$ & 46,5 \\
\hline Suécia & 1,3 & 30,5 & $-1,2$ & 44,4 & $-2,8$ & 68,0 & n.d. & 88,0 & $-12,3$ & 52,9 \\
\hline Modelo corporativista & 3,3 & 31,6 & 2,1 & 42,8 & $-1,1$ & 25,2 & 2,2 & 86,4 & 1,0 & 62,2 \\
\hline França & 3,3 & 34,2 & 3,4 & 47,4 & 0,5 & 8,0 & 0,0 & 98,0 & $-2,5$ & 51,8 \\
\hline Áustria & 2,3 & 30,2 & 2,2 & 43,5 & $-2,9$ & 27,0 & 0,0 & 95,0 & 6,9 & 80,5 \\
\hline Alemanha & 1,8 & 29,5 & 0,8 & 39,3 & $-1,9$ & 18,0 & 14,0 & 62,0 & $-2,3$ & 46,4 \\
\hline Bélgica & 3,9 & 30,8 & 2,4 & 46,2 & 0,3 & 55,0 & 0,0 & 96,0 & 4,7 & 72,7 \\
\hline Holanda & 5,0 & 33,3 & 1,6 & 37,8 & $-1,3$ & 18,0 & n.d. & 81,0 & $-1,9$ & 59,6 \\
\hline Modelo mediterrânico & 4,6 & 28,6 & 1,4 & 38,0 & 0,4 & 24,0 & 11,4 & 76,8 & $-6,9$ & 48,3 \\
\hline Itália & 3,7 & 30,3 & 1,9 & 43,4 & 2,5 & 36,0 & $-16,0$ & 80,0 & $-22,0$ & 52,5 \\
\hline Grécia & 6,4 & 31,2 & 4,9 & 38,2 & $-3,5$ & 21,0 & n.d. & 65,0 & $-2,2$ & 53,9 \\
\hline Portugal & 3,0 & 26,9 & 2,1 & 37,0 & 0,2 & 21,0 & n.d. & 92,0 & $-6,6$ & 34,6 \\
\hline Espanha & 5,1 & 25,9 & $-3,3$ & 33,5 & 2,3 & 18,0 & 0,0 & 70,0 & 3,4 & 52,2 \\
\hline Modelo liberal & 9,3 & 30,7 & $-1,2$ & 32,6 & $-1,2$ & 28,5 & $-6,0$ & 36,5 & $-2,3$ & 76,3 \\
\hline Reino Unido & 4,1 & 28,8 & $-1,3$ & 34,5 & $-1,9$ & 26,0 & $-6,0$ & 29,0 & $-5,9$ & 73,1 \\
\hline Irlanda & 14,5 & 32,5 & $-1,1$ & 30,7 & $-0,5$ & 31,0 & n.d. & 44,0 & 1,3 & 79,5 \\
\hline
\end{tabular}

Fonte: EUROSTAT, OCDE, ILO (Internacional Labor Organization) e Heritage Foundation Data Bases.

Quadro $9 \triangleright$ Despesa com proteção social (em percentagem do PIB), por principais destinatários das transferências efetuadas (evolução entre 2007 e 2012)

\begin{tabular}{|c|c|c|c|c|}
\hline & $\begin{array}{l}\text { Terceira idade } \\
\text { e sobrevivência }\end{array}$ & $\begin{array}{c}\text { Doença } \\
\text { e deficiência }\end{array}$ & Famílias e crianças & Desempregados \\
\hline Modelo social-democrata & 2,0 & 0,7 & 0,3 & 0,3 \\
\hline Dinamarca & 1,8 & 1,0 & 0,0 & 0,6 \\
\hline Finlândia & 2,9 & 1,6 & 0,5 & 0,2 \\
\hline Suécia & 1,2 & $-0,4$ & 0,3 & 0,1 \\
\hline Modelo corporativista & 1,3 & 1,5 & 0,0 & 0,2 \\
\hline França & 1,7 & 0,9 & 0,0 & 0,1 \\
\hline Austria & 1,6 & 0,5 & 0,1 & 0,1 \\
\hline Alemanha & 0,0 & 1,7 & 0,4 & $-0,3$ \\
\hline Bélgica & 1,5 & 1,7 & 0,0 & 0,5 \\
\hline Holanda & 1,6 & 2,6 & $-0,5$ & 0,7 \\
\hline Modelo mediterrânico & 3,3 & 0,1 & 0,1 & 0,9 \\
\hline Itália & 2,4 & 0,6 & 0,2 & 0,5 \\
\hline Grécia & 5,3 & $-0,2$ & 0,1 & 0,8 \\
\hline Portugal & 2,6 & $-0,5$ & 0,0 & 0,6 \\
\hline Espanha & 2,9 & 0,6 & 0,1 & 1,6 \\
\hline Modelo liberal & 2,2 & 5,2 & 0,5 & 1,2 \\
\hline Reino Unido & 2,2 & 1,7 & 0,2 & 0,2 \\
\hline Irlanda & 2,2 & 8,7 & 0,8 & 2,2 \\
\hline
\end{tabular}

Fonte: EUROSTAT Data Base.

O facto de ter ocorrido uma aproximação entre os quatro modelos-tipo, em termos de peso da despesa com proteção social e com impostos e contribuições sociais, manten- do-se apenas acentuadas diferenças entre sistemas de relações laborais, parece ter contribuído para a aproximação que também ocorreu em termos de desempenhos económicos. No entanto, 
Quadro $10 \triangleright$ Desempenho económico ao longo das crises

\begin{tabular}{lccc} 
Modelo social-democrata & $\begin{array}{c}\text { Evolução do PIB } \\
\text { entre 2008 } \mathbf{2 0 1 3} \\
(\mathbf{2 0 0 5 = 1 0 0 )}\end{array}$ & $\begin{array}{c}\text { Evolução da taxa } \\
\text { de desemprego } \\
\text { entre } \mathbf{2 0 0 7} \text { e 2014 }\end{array}$ & $\begin{array}{c}\text { Taxa } \\
\text { de desemprego } \\
\text { em 2014 }\end{array}$ \\
\hline Dinamarca & $\mathbf{1 3 , 3}$ & $\mathbf{2 , 1}$ & $\mathbf{7 , 7}$ \\
Finlândia & 10,3 & 2,8 & 6,6 \\
Suécia & 10,7 & 1,8 & 8,7 \\
Modelo corporativista & 19,0 & 1,8 & 7,9 \\
\hline França & $\mathbf{7 , 6}$ & $\mathbf{0 , 7}$ & $\mathbf{7 , 4}$ \\
Áustria & 6,2 & 2,3 & 10,3 \\
Alemanha & 9,2 & 0,7 & 5,6 \\
Bélgica & 7,6 & $-3,5$ & 5,0 \\
Holanda & 9,8 & 1,0 & 8,5 \\
Modelo mediterrânico & 5,1 & 3,2 & 7,4 \\
\hline Itália & $\mathbf{3 , 6}$ & $\mathbf{1 1 , 5}$ & $\mathbf{1 9 , 5}$ \\
Grécia & 7,5 & 6,6 & 12,7 \\
Portugal & 2,3 & 18,1 & 26,5 \\
Espanha & 3,5 & 4,9 & 14,1 \\
Modelo liberal & 0,9 & 16,3 & 24,5 \\
\hline Reino Unido & $\mathbf{0 , 0}$ & $\mathbf{3 , 7}$ & $\mathbf{8 , 7}$ \\
Irlanda & 3,8 & 0,8 & 6,1 \\
& $-3,7$ & 6,6 & 11,3
\end{tabular}

Fonte: EUROSTAT Data Base.

um melhor desempenho médio dos estados corporativistas e social-democratas, na contenção do aumento do desemprego, foi, pelo menos até 2014, evidente.
Em 2013, cinco anos após a crise de 2008, os desempenhos sociais eram, com exceção do modelo mediterrânico, já muito semelhantes nos quatro modelos-tipo (Quadro 11).

Quadro 11 Desempenho social em 2013

\begin{tabular}{|c|c|c|c|c|}
\hline \multirow[b]{3}{*}{ Modelo social-democrata } & \multicolumn{2}{|c|}{$\begin{array}{l}\text { Desigualdade económica } \\
\text { (índice de Gini) }\end{array}$} & \multicolumn{2}{|c|}{$\begin{array}{l}\text { Risco de pobreza (em \% da população } \\
\text { residente) }\end{array}$} \\
\hline & $\begin{array}{c}\text { (antes } \\
\text { de transferências } \\
\text { sociais) }\end{array}$ & $\begin{array}{l}\text { (depois } \\
\text { de transferências } \\
\text { sociais) }\end{array}$ & $\begin{array}{l}\text { (antes } \\
\text { de transferências } \\
\text { sociais) }\end{array}$ & $\begin{array}{c}\text { (depois } \\
\text { de transferências } \\
\text { sociais) }\end{array}$ \\
\hline & 51,0 & 25,9 & 41,9 & 13,0 \\
\hline Dinamarca & 53,0 & 27,5 & 41,8 & 12,3 \\
\hline Finlândia & 46,5 & 25,4 & 41,7 & 11,8 \\
\hline Suécia & 53,4 & 24,9 & 42,3 & 14,8 \\
\hline Modelo corporativista & 49,1 & 27,6 & 42,3 & 13,9 \\
\hline França & 50,3 & 30,1 & 44,7 & 13,7 \\
\hline Áustria & 47,0 & 27,0 & 44,1 & 14,4 \\
\hline Alemanha & 56,4 & 29,7 & 43,7 & 16,1 \\
\hline Bélgica & 47,1 & 25,9 & 42,0 & 15,1 \\
\hline Holanda & 44,9 & 25,1 & 37,2 & 10,4 \\
\hline Modelo mediterrânico & 53,9 & 33,7 & 47,8 & 20,3 \\
\hline Itália & 48,9 & 32,5 & 45,2 & 19,1 \\
\hline Grécia & 61,6 & 34,4 & 53,4 & 23,1 \\
\hline Portugal & 55,9 & 34,2 & 46,9 & 18,7 \\
\hline Espanha & 49,3 & 33,7 & 45,5 & 20,4 \\
\hline Modelo liberal & 54,5 & 30,1 & 47,5 & 15,0 \\
\hline Reino Unido & 54,5 & 30,2 & 45,2 & 15,9 \\
\hline Irlanda & 54,5 & 30,0 & 49,8 & 14,1 \\
\hline
\end{tabular}

Fonte: EUROSTAT Data Base. 


\section{Conclusão}

Os dados oficiais disponíveis e selecionados para este estudo sugerem que as reformas nacionais efetuadas nos regimes de proteção social, nos sistemas fiscais e contributivos e nos sistemas de relações entre capital e trabalho resultaram num mais generalizado, a toda a União, trade off entre menor crescimento económico e menos injusta distribuição do (menor) rendimento por ele gerado. Ou seja, a um menor mas mais justamente partilhado bem-estar.

Apesar da redução dos desempenhos sociais dos estados social-democratas e corporativistas, os melhores desempenhos sociais dos estados (antes da crise) liberais permitiu reduzir, no conjunto da União, os índices de desigualdade económica e o risco de pobreza. De fora deste processo ficou apenas a maioria dos estados mediterrânicos, em larga medida devido à persistência dos desequilíbrios e às incongruências que sempre caraterizaram o modelo mediterrânico.

Os desempenhos dos estados social-democratas e corporativistas sugerem que competitividade, crescimento económico e emprego são compatíveis com níveis, não excessivamente desiguais, de distribuição do rendimento entre capital, trabalho e inatividade. A demonstração de que menor crescimento pode ser compensado por uma mais justa distribuição do rendimento e do bem-estar que o mesmo torna, apesar de tudo, possível não permite ignorar, no entanto, que o crescimento conseguido não foi, pelo menos até 2014, suficiente para garantir o acesso a um rendimento oriundo do trabalho a pelo menos dez por cento da população ativa residente na União e, em especial, a, em média, vinte por cento da população ativa residente nos estados mediterrânicos.

Encontrar um ponto de equilíbrio que assegure a não-exclusão do direito ao trabalho de significativa parte da população ativa constitui claramente um dos mais importantes desafios que se colocam atualmente à União. No entanto, dado que pontos de equilíbrio, entre crescimento, emprego e igualdade, não-discriminação, solidariedade e razoavelmente justa distribuição do rendimento, foram conseguidos por estados social-democratas e corporativistas antes e após a crise de 2008, a tarefa não parece ser impossível. Reajustar os regimes de proteção social, os sistemas fiscais e contributivos e os sistemas de relações laborais de forma a encontrar um equilíbrio entre os interesses do capital e os interesses do trabalho será, no entanto, porventura mais fácil do que encontrar uma solução para o peso crescente da inatividade, quer da provocada pelo desemprego, em particular entre a população mais jovem, quer da decorrente do gradual envelhecimento da população residente na União. Neste caso, apesar de experiências nacionais ou regionais não poderem ser facilmente transpostas para realidades culturais e socioeconómicas diferentes, os desempenhos recentes dos estados social-democratas e corporativistas poderão constituir uma boa referência para o futuro.

\section{Notas}

1 Dada a sua pequena dimensão e o peso desproporcionado que teriam nos valores médios de cada modelo ideal-típico, optou-se por não considerar, para efeitos deste estudo, os seguintes estados-membros da União: Chipre, Luxemburgo e Malta. Os estados-membros oriundos do designado ex-bloco soviético também não foram incluídos na análise, por não estarem disponíveis, para a totalidade do período temporal considerado, a maioria dos dados empíricos necessários ao estudo em causa.

2 Bases de dados disponíveis online em ec.europa.eu/ eurostat/data/database e em stats.oecd.org/Index. aspx?DataSetCode.

3 O índice de Gini mede o coeficiente de distribuição estatística do rendimento mediano disponível e varia entre 0 (desigualdade nula) e 100 (desigualdade máxima).

4 Percentagem da população com um rendimento inferior a $60 \%$ do rendimento mediano equalizado.

5 O freedom labor index foi criado por uma fundação privada ultraliberal, a Heritage Foundation, e reflete, numa escala de 0 (nenhuma liberdade ou flexibilidade), a 100 (total liberdade ou flexibilidade), um conjunto de constrangimentos, legais e sindicais, colocados à contratualização e ao despedimento de trabalhadores assalariados. Base de dados disponível online em www.heritage.org/index/ labor-freedom.

6 Bases de dados disponíveis online em laborsta.ilo.org/ applv8/data/TUM/TUD\%20and\%20CBC\%20Technical\%20 Brief.pdf e em www.heritage.org/index/labor-freedom.

\section{Referências bibliográficas}

AIGINGER, K. e T. Leoni (2009), Typologies of social models in Europe, WIFO Working Paper.

BARR, N. (2001), Welfare State as Piggy Bank: Information, Risk, Uncertainty, and the Role of the State, Oxford, Oxford University Press.

BLYTH, M. (2002), Great Transformations: Economic Ideas and Institutional Change in the Twentieth Century, Cambridge, Cambridge University Press.

BONOLI, G. (1997), "Classifying Welfare States: a Two-Dimension Approach", Journal of Social Policy, 26 (3), pp. 351-372.

BRIDGEN, P. e T. Meyer (2014), "The Liberalisation of the German Social Model: Public-Private Pension Reform in Germany since 2001", Journal of Social Policy, 43 (1), pp. 37-68.

DØLVIK, J. e A. Martin (eds.) (2014), European Social Models from Crisis to Crisis: Employment and Inequality in the Era of Monetary Integration, Oxford, Oxford University Press.

EMMENEGGER, P. (2011), "How good are your counterfactuals? Assessing quantitative macro-com- 
parative welfare state research with qualitative criteria", Journal of European Social Policy, 21, pp. 365-380.

ESPING-ANDERSEN, G. (1990), Three Worlds of Welfare Capitalism, Cambridge, Cambridge Polity Press.

ESPING-ANDERSEN, G. (1996), "Welfare states without work: the impasse of labour shedding and familialism in continental European social policy", in G. Esping-Andersen (Ed.), Welfare States in Transition, Londres, Sage, pp. 66-87.

ESPING-ANDERSEN, G. (2000), "Two societies, one sociology, and no theory", The British Journal of Sociology, 51 (1), pp. 59-77.

ESPING-ANDERSEN, G. (2005), "Education and Equal Life Chances: Investing in Children", in O. Kangas, e J. Palme (eds.), Social Policy and Economic Development in the Nordic Countries, Basingstoke, Palgrave-Macmillan/UNRISD, pp. 147-163.

FERRERA, M. (1996), "The «Southern Model» of Welfare in Social Europe", Journal of European Social Policy, 6 (1), pp. 17-37.

GHAUSSY, A. G. e W. Schäfer (eds.) (2002), The economics of German unification, Londres, Routledge.

HEMERIJCK, A. (2013), Changing Welfare States, Oxford, Oxford University Press.

HERMANN, C. (2014a), "Crisis, structural reform and the dismantling of the European Social Model(s)", Economic and Industrial Democracy, 17, pp. 1-18.

HERMANN, C. (2014b), "Structural adjustment and neoliberal convergence in labour markets and welfare: The impact of the crisis and austerity measures on European Economic and Social Models", Competition \& Change, 18 (2), pp. 111-130.

HERMANN, C. e I. Hofbauer (2007), "The European Social Model: Between Competitive Modernisation and Neoliberal Resistance", Capital and Class: Conference Socialist Economist, 31, pp. 125-139.

HONKAPOHJA, S. e E. Koskela (1999), "The economic crisis of the 1990s in Finland", Economic Policy, 14 (29), pp. 400-436.
HUBER, E. e J. Stephens (2005), "Welfare states and the economy", The Handbook of Economic Sociology, Nova Iorque, Russell Sage Foundation.

HYMAN, R. (2005), "Trade unions and the politics of the European social model", Economic and Industrial Democracy, 26 (1), pp. 9-40.

KANGAS, O. e J. Palme (2009), "Making Social Policy Work for Economic Development: The Nordic Experience", International Journal of Social Welfare, 18, pp. 62-72.

KRUGMAN, P. (2008), The Conscience of a Liberal, Nova Iorque, W. W. Norton \& Company.

KWON, H. et al. (2009), "Introduction: Social Policy and Economic Development in Late Industrializers", International Journal of Social Welfare, 18, pp. $1-11$.

LEIBFRIED, S. (2000), "Towards a European Welfare State?", in C. Pierson e F. Castles (eds.), The Welfare State Reader, Cambridge, Polity Press, pp. 190-206.

OKUN, A. (1975), Equality and Efficiency: The Big Tradeoff, Washington, Brookings Institution Press.

PIERSON, P. (1994), Dismantling the Welfare State?, Cambridge, Cambridge University Press.

RYNER, M. (1999), "Neoliberal globalization and the crisis of Swedish social democracy", Economic and Industrial Democracy, 20 (1), pp. 39-79.

SAPIR, A. (2006), "Globalization and the reform of European social models", Journal of Common Market Studies, 44 (2), pp. 369-390.

STRONACH, I. (1990), "The Rituals of Recovery: UK Education and Economic «Revival» in the 70 s and 80s", Anthropology Today, 6 (6), pp. 4-8.

WOOD, G. et al. (2014), "Comparative capitalism without capitalism, and production without workers: the limits and possibilities of contemporary institutional analysis", International Journal of Management Reviews, 16 (4), pp. 384-396.

VAN KERSBERGEN, K. e A. Hemerijck (2012), "Two decades of change in Europe: the emergence of the social investment state", Journal of Social Policy, 41 (3), pp. 475-492. 